\title{
A UV absorbing compound in HPLC pigment chromatograms obtained from Icelandic Basin phytoplankton
}

\author{
C. A. Llewellyn*, R. F. C. Mantoura \\ Plymouth Marine Laboratory, Prospect Place, West Hoe, Plymouth PL1 3DH, United Kingdom
}

\begin{abstract}
A UV absorbing compound was observed in surface waters of the Iceland Basin during the decline of a phytoplankton bloom in June 1989. The compound elutes early during reverse-phase HPLC analyses of phytoplankton chlorophylls and carotenoids and has a broad absorption band from 300 to $470 \mathrm{~nm}$ with an absorption maximum at $380 \mathrm{~nm}$. The compound (subsequently referred to as P380) is characterised by similar, but not identical, elution properties and absorption spectrum to scytonemin, an ultraviolet sunscreen pigment not previously found in the phytoplankton. The similarity of P380 to mycosporine-like amino acids (MAAs) is also discussed. P380 concentrations are highest in surface waters, decline sharply within the upper euphotic zone, and are linearly correlated $\left(r^{2}=0.68\right)$ with the photoprotective carotenoid diadinoxanthin.
\end{abstract}

KEY WORDS: UV absorbing compound P Pigments Phytoplankton $\cdot$ HPLC $\cdot$ Iceland Basin

Increased UV-B (280 to $320 \mathrm{~nm}$ ) irradiance associated with stratospheric ozone depletion over Antarctica has led to a recent surge in scientific interest in UV absorbing compounds, in particular the mycosporinelike amino acids (MAAs) in phytoplankton (Carreto et al. 1989, 1990, Vernet et al. 1989, Karentz et al. 1991, Negri et al. 1992, Garcia-Pichel et al. 1993). In the Northern Hemisphere, ozone depletion is a more recent phenomenon (Roy et al. 1990, Stolarski et al. 1992, Frederick \& Erlick 1995, Schindler et al. 1996) and studies on UV absorbing compounds in the phytoplankton are as a result lacking. In this note we report a UV absorbing compound which we detected during the HPLC analyses of pigments from surface waters of the Iceland Basin. The compound (subsequently referred to as P380) eluted early in the pigment chromatograms and had broad absorption between 300 and $470 \mathrm{~nm}$ with an absorption maximum of $380 \mathrm{~nm}$.

-E-mail: call@pml.ac.uk
P380 resembled scytonemin which is an extracellular photoprotecting pigment found in cyanobacterial mats (Garcia-Pichel \& Castenholz 1991, Vincent et al. 1993) but which has not been reported in phytoplankton. We also compare P380's chromatographic and spectral absorption properties to those of the MAAs.

Methods. Samples were collected during the North Atlantic Bloom Experiment in June 1989 under the auspices of the UK-JGOFS programme (Weeks et al. 1993). Surface particulate samples were collected along a transect from Troon, Scotland to the Iceland Basin (Fig. 1), and water column samples with detailed physical and chemical measurements were taken in the Iceland Basin and at $56^{\circ} \mathrm{N}, 20^{\circ} \mathrm{W}$ (Weeks et al. 1993). Sampling, analysis and quantification of the phytoplankton pigments were according to Llewellyn \& Mantoura (1996). The chromatographic detection wavelength was set at $440 \mathrm{~nm}$ and spectra were collected between 300 and $700 \mathrm{~nm}$ using an on-line diode array absorption spectrophotometer (Waters 990).

Results. P380 distribution and properties: P380 had a retention time of $1.5 \mathrm{~min}$ on the chromatogram (Fig. 2A) and its spectrum had a broad absorption band from 300 to $470 \mathrm{~nm}$ with a maximum at 380 to $383 \mathrm{~nm}$ in the HPLC eluent (Fig. 3A), i.e. spanning mainly the UV-A (320 to $400 \mathrm{~nm}$ ) but. with some absorption in the UV-B (280 to $320 \mathrm{~nm}$ ) and visible (400 to $700 \mathrm{~nm}$ ) regions of the light spectrum. The lipid solubility, early elution on the HPLC and the prominant spectral absorption maximum of P380 matched scytonemin (Garcia-Pichel \& Castenholz 1991, Vincent et al. 1993). A microbial mat extract rich in scytonemin was obtained from R. Castenholz (University of Oregon, USA) for a comparison of properties on our system. HPLC analysis of this microbial mat extract produced 3 peaks (Fig. 2B). Peak a, eluted at $1.4 \mathrm{~min}$, showed absorption maxima at 442 and $575 \mathrm{~nm}$ with a shoulder at $370 \mathrm{~nm}$ and did not resemble P380. Peak b, eluted at 


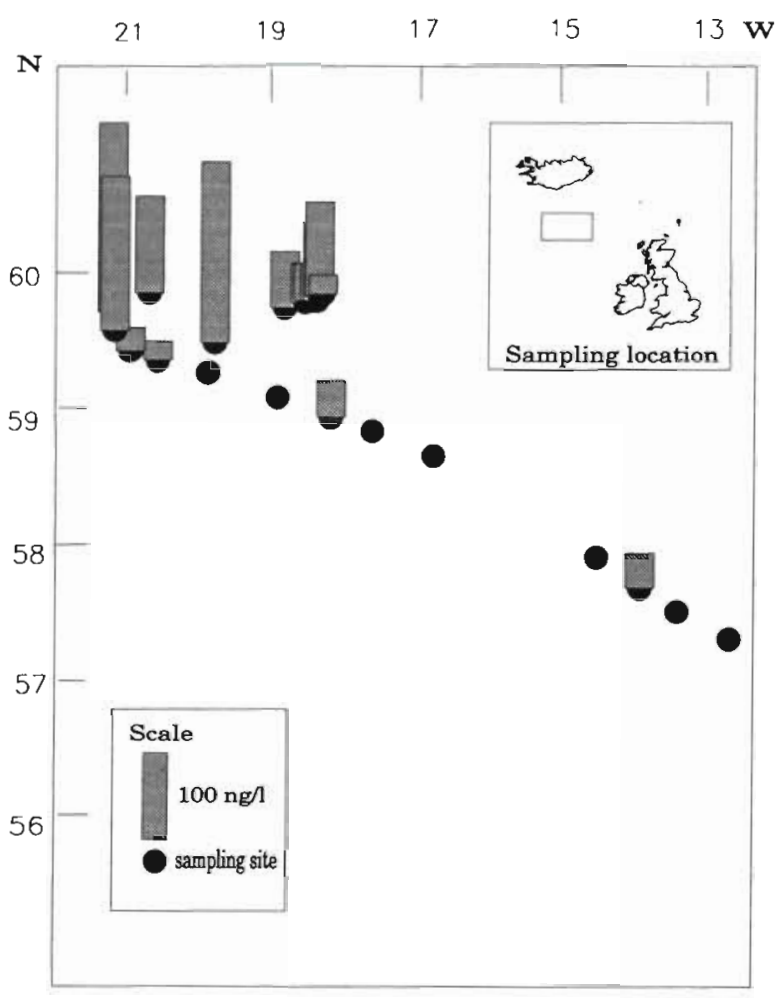

Fig. 1. Main sampling location sites in and around the Iceland Basin together with surface concentrations of the UV absorbing compound, P380, calculated using the scytonemin extinction coefficient of $4.5 \mathrm{l} \mathrm{g}^{-1} \mathrm{~cm}^{-1}$

$1.8 \mathrm{~min}$, had a maximum at $385 \mathrm{~nm}$ with a shoulder at $450 \mathrm{~nm}$, and corresponded to the red reduced form of scytonemin (Garcia-Pichel \& Castenholz 1991). Peak c, the largest peak, eluted at $4.5 \mathrm{~min}$, had a spectrum that matched those published for scytonemin (GarciaPichel \& Castenholz 1991, Vincent et al. 1993) and resembled the $\mathrm{P} 380$ spectrum apart from a $5 \mathrm{~nm}$ bathochromic shift (Fig. 3).

P380 was found in all surface water vertical profiles undertaken at $60^{\circ} \mathrm{N}$. It was also found in discrete samples taken en route to $60^{\circ} \mathrm{N}$ (Fig. 1). There were no underway samples between $59^{\circ}$ and $56^{\circ} \mathrm{N}$, and samples collected at $56^{\circ} \mathrm{N}$ and turther south revealed no P380. Concentrations were estimated from peak area assuming a scytonemin extinction coefficient of $45 \mathrm{l} \mathrm{g}^{-1}$ $\mathrm{cm}^{-1}$ at $440 \mathrm{~nm}$ (Vincent et al, 1993); this produced a detection limit of $20 \mathrm{ng} \mathrm{l^{-1 }}$ at $440 \mathrm{~nm}$ for $2 \mathrm{l}$ of filtered seawater. Concentrations were generally highest in the surface where they ranged from 22 to $250 \mathrm{ng} \mathrm{l}^{-1}$ and then decreased rapidly to below detection limit at 20 to $50 \mathrm{~m}$. A typical example (15 June 1989) showed a distinct chlorophyll a (chl a) maximum at $10 \mathrm{~m}$ with declining concentrations of P380 from $179 \mathrm{ng}^{-1}$ in the surface to below detection limit at $25 \mathrm{~m}$ (Fig. 4). An exception was on 19 June 1989, when the water col-

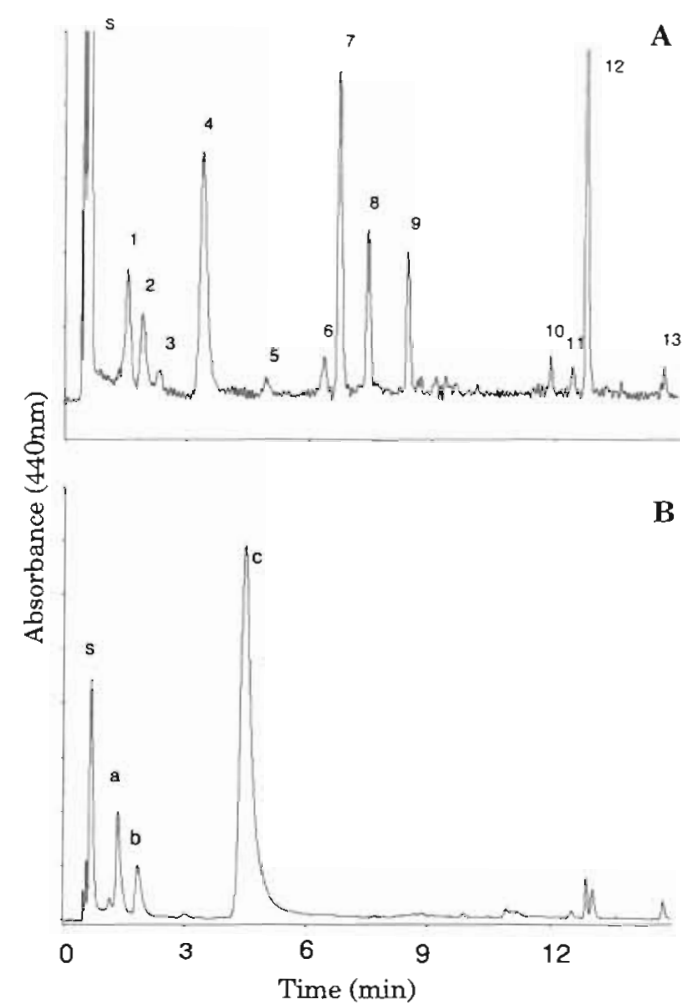

Fig. 2. (A) HPLC absorbance chromatogram of P380 and chlorophylls and carotenoids in water column particulates from the Iceland Basin. Peak identification: $1, \mathrm{P} 380 ; 2$, chlorophyll $c_{3} ; 3$, chlorophyllide $a_{;} 4$, chlorophyll $c_{1} \& c_{2} ; 5$, peridinin 6, 19'butanoyloxyfucoxanthin; 7 , fucoxanthin; 8,19 'hexanoyloxyfucoxanthin $; 9$, diadinoxanthin; 10 , chlorophyll $b ; 11$, chlorophyll $a$ allomer; 12 , chlorophyll $a ; 13, \beta-\beta$ carotene. (B) HPLC chromatogram of acetone extract from a microbial mat sample rich in scytonemin (courtesy of $\mathrm{R}$. Castenholz, University of Oregon, USA). Peak identification: s, solvent front; $a$, scytonemin derivative; $b$, scytonemin derivative; c, scytonemin

umn was well mixed and there was no distinct chl a maximum (Weeks et al. 1993); here the P380 concentrations were more uniform and could be detected

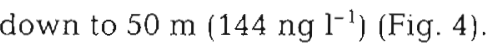

Photosynthetic pigments in the Iceland Basin: Conditions in the Iceland Basin during June 1989 were those of a late phytoplankton bloom with weak and intermittent stratification, high nutrient concentrations, and high and variable phytoplankton biomass and production (Weeks et al. 1993). Surface chl a concentrations varied between 0.4 and $1 \mu \mathrm{g} \mathrm{l}^{-1}$ with maximum chl a concentrations of 0.6 to $1 \mu \mathrm{g} \mathrm{l}^{-1}$ found at depths varying between 5 and $50 \mathrm{~m}$. Pigment signatures indicated that the phytoplankton biomass in the upper water column was dominated by diatoms, with prymnesiophytes and to a much lesser extent dinoflagellates also present (Weeks et al. 1993, Llewellyn \& Mantoura 1996). Fucoxanthin and 19'hexanoyloxyfu- 

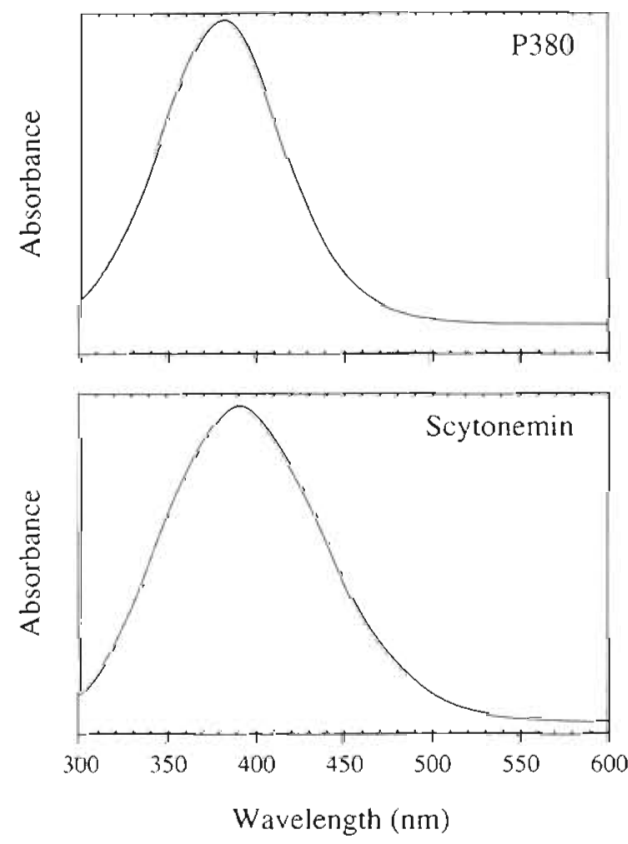

Fig. 3. On-line diode array spectrum of P380 and scytonemin

coxanthin levels tended to track those of chl $a$, whilst peridinin and diadinoxanthin concentrations were at their highest in surface samples $\left(0.06\right.$ and $0.2 \mu \mathrm{g} \mathrm{l}^{-1}$ respectively). Examples of vertical depth profiles of diadinoxanthin concentrations along with those of P380 and chl a are shown in Fig. 4. Diadinoxanthin was the only pigment to give a significant correlation when linearly regressed against P380 for the upper $10 \mathrm{~m}\left(\mathrm{r}^{2}=\right.$ $0.68, p<0.01, n=17$ for diadinoxanthin, $r^{2}<0.2$ for chl a, peridinin, 19'hexanoyloxyfucoxanthin and fucoxanthin).
Discussion. Similiarity of P380 to scytonemin and MAAs: The spectrum and HPLC elution characteristics of P380 are similar to scytonemin, indicating that P380 maybe structurally related to scytonemin. Scytonemin is an extracellular UV sunscreen pigment thought to provide resistance to both photobleaching of $\mathrm{chl} a$ and to photoinhibition of photosynthesis by UV-A (GarciaPichel et al. 1992). Its synthesis is induced by high irradiance, most effectively by UV-A and UV-B, and its concentration varies directly with UV flux (Proteau et al. 1993). Although scytonemin has widespread occurrence in sheathed cyanobacteria from diverse geographical locations exposed to high solar irradiance, it has not been recorded in phytoplankton (Garcia-Pichel \& Castenholz 1991). Garcia-Pichel \& Castenholz (1991) have shown several forms of scytonemin to be present and suggest minor differences in scytonemin may exist in different cyanobacterial species. If P380 is related to scytonemin, this is the first reporting of such a product in phytoplankton.

P380 could alternatively be related to MAAs. These are water soluble intracellular molecules which have been reported in a wide variety of marine organisms including phytoplankton and mostly have absorption maxima between 310 and $360 \mathrm{~nm}$ (e.g. Karentz et al. 1991, Shick et al. 1992, Carreto et al. 1989). MAAs have been reported in dinoflagellates (Carreto et al. 1989, 1990, Vernet et al. 1989, Negri et al. 1992) and in the phytoplanktonic cyanobacteria Gloeocapsa sp. (Garcia-Pichel et al. 1993). S. W. Jeffrey, H. Smith, M. Vesk \& K. Groenewoud (unpubl.) report high UV: chl a absorbance ratios in methanol:tetrahydrofuran extracts of surface bloom-forming dinoflagellates, cryptomonads and raphidophytes. Absorption maxima in the extracts occurred between 280 and $378 \mathrm{~nm}$, the

Pigment Concentration, ng $/$ and Downwelling Irradiance, $\mu \mathrm{E} / \mathrm{m} 2 / \mathrm{s}$
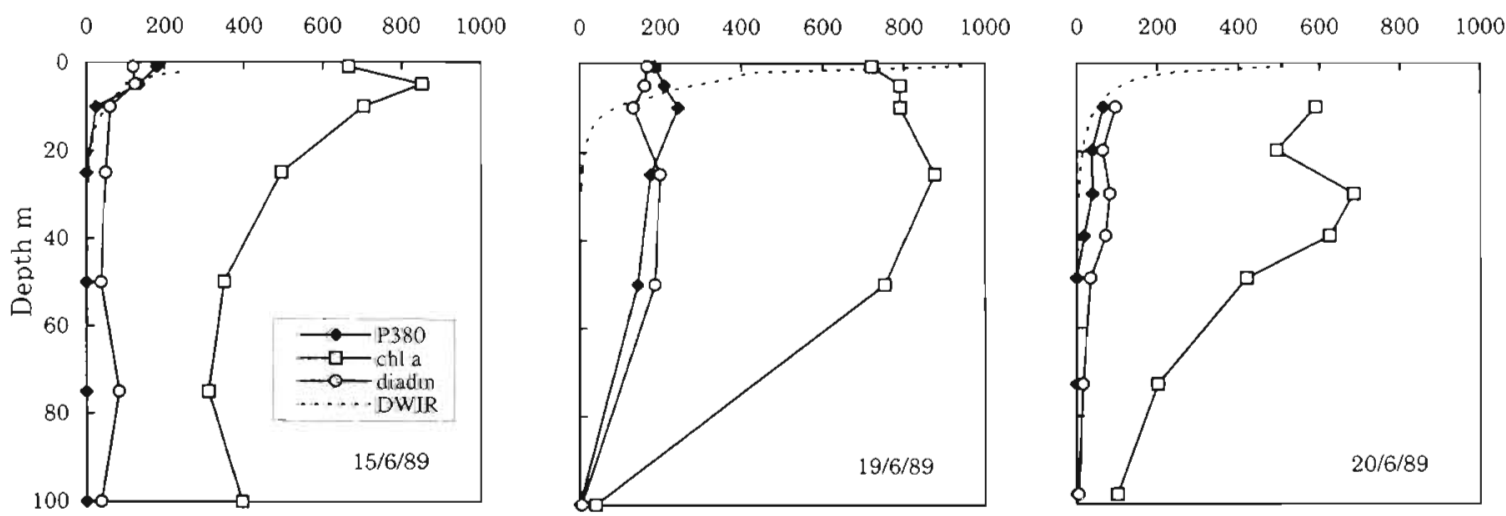

Fig. 4. Vertical depth profiles of P380, chlorophyll $a$ and diadinoxanthin alongside downwelling irradiance (DWIR) for photosynthetically active radiation (400 to $700 \mathrm{~nm}$ ) obtained using a $2 \pi$ PAR meter. The DWIR profiles for 19 and 20 June 1989 pertain to the actual pigment casts, whereas for 15 June 1989 a daytime profile is plotted 
latter in a dinoflagellate Gymnodinium catenatum bloom. In the same study HPLC MAA analysis of other species including strains of $G$. catenatum revealed MAAs with absorption maxima from 323 to $369 \mathrm{~nm}$. In our study, dinoflagellate levels as indicated by peridinin were generaily low compared to further south but were highest in the surface water. Gyrodinium sp. was the dominant dinoflagellate and its concentrations were highest in the upper $20 \mathrm{~m}$ of the water column (Derek Harbour, PML, unpubl. data)

Most MAAs are too strongly acidic to be separated during HPLC pigment analysis and are generally analysed using reverse-phase C8 chromatography with $0.1 \%$ acetic acid and $25 \%$ methanol (v/v) (Karentz et al. 1991). The more weakly acidic MAAs, such as palythine, asterina-330, palythinol and palythene, however, could elute early in pigment chromatograms. Palythene, as well as being the least polar MAA commonly encountered in marine organisms, is also the most highly conjugated molecule with an absorption maximum of $360 \mathrm{~nm}$ in $80 \%$ methanol (Karentz et al. 1991). It might then be that $P 380$ is a previously unreported relatively non-polar MAA. However, as the properties of P380 do not exactly match those of MAAs or scytonemin it might be that P380 is an entirely different UV absorbing compound.

P380 association with diadinoxanthin: Diadinoxanthin is found in diatoms, prymnesiophytes and dinoflagellates and is a photoprotective carotenoid which undergoes light-induced reversible de-epoxidationepoxidation reactions (Hager 1980, Arsalane et al. 1994). The occurrence of diadinoxanthin and UV absorbing compounds matching those of MAAs have also been observed by Vernet et al. (1989) in blooms of the red-tide dinoflagellates Prorocentrum micans and Gonyaulax polyedra. They concluded that both the UV absorbing compounds and diadinoxanthin play protective roles in screening harmful radiation in red-tide dinoflagellates exposed to high light conditions.

The correlation between diadinoxanthin and P380 does not, however, imply that diadinoxanthin and P380 co-occur in the same class of phytoplankton. Diatoms are tolerant to high UV irradiance but produce only low concentrations of UV absorbing substances (Davidson et al. 1994). A correlation between diadinoxanthin and UV absorbing compounds could occur during high UV irradiance of a mixed phytoplankton population with diatoms producing increased diadinoxanthin and other classes producing UV absorbing compounds.

UV/vis irradiance: Increased UV and visible radiation is likely to result in physiological and behavioural adaption of surface water phytoplankton (Calkins \& Thordardottir 1980, Davidson 1996). The majority of photoinhibition caused by solar UVR is in the UV-A.
(Buhlmann et al. 1987, Helbling et al. 1992) and UV-A radiation has been found to have a detrimental effect. on cellular processes (Karentz \& Lutz 1990). We did not measure UV radiation during our study but measurements by the National Radiological Board (Driscoll et al. 1990) at 3 sites in the UK including 1 in Glasgow $\left(56^{\circ} \mathrm{N}\right)$ showed highest levels of UV-A, UV-B and visible radiation during 1989 to concur with our study in June. Measurements of downwelling photosynthetically active radiation ( 400 to $700 \mathrm{~nm}$ ) are plotted alongside the pigment profiles in Fig. 4 and produce 1\% penetration depths of between 20 and $30 \mathrm{~m}$. Using calculated attenuation coefficients for $800 \mathrm{ng}$ chlorophyll $\mathrm{l}^{-1}$ of 0.106 and $0.136 \mathrm{~m}^{-1}$ for 440 and $380 \mathrm{~nm}$ respectively (Morel \& Antoine 1994), the $1 \%$ penetration depth would be at 43 and $34 \mathrm{~m}$ for 440 and $380 \mathrm{~nm}$ respectively. The decline in $\mathrm{P} 380$ concentrations from the surface down to the depths that UV and PAR can penetrate suggests that P380 may have a photoprotective role in response to high light intensity and increased UV irradiation. Clearly these preliminary observations on P380 need further investigation to ascertain the abundance, structural identification and importance of P380 in the phytoplankton.

Acknowledgements. We thank Richard Castenholz for generously providing a scytonemin extract, Ray Barlow, Jim Readman. Shirley Jeffrey and Richard Geider for valuable discussions and critical review and Denise Cummings for technical assistance. We are also grateful for the reviewers' comments.

\section{LITERATURE CITED}

Arsalane W, Rousseau B, Duval JC (1994) Influence of the pool size of the xanthophyll cycle on the effects of light stress in a diatom: competition between photoprotection and photoinhibition. Photochem Photobiol 60:237-243

Booth CR, Morrow JH (1997) The penetration of UV into natural waters. In: Impacts of solar UVR on aquatic microorganisms. Photochem Photobiol 65:252-269

Buhlmann B, Bossard P, Uehlinger U (1987) The influence of longwave radiation (UV-A) on photosynthetic activity $\left({ }^{14} \mathrm{C}\right.$-assimilation) of phytoplankton. J Plankton Res 9 935-943

Calkins J, Thordardottir T (1980) The ecological significance of solar UV radiation on aquatic organisms. Nature 283 $563-566$

Carreto JI, Carignan MO, Daleo G, De Marco SG (1990) Occurrence of mycosporine-like amino acids in the redtide dinoflagellate Alexandrium excavatum: UV photoprotective compounds? J Plankton Res 12:909-921

Carreto JI, De Marco SG, Lutz VA (1989) UV-absorbing pigments in the dinoflagellates Alexandrium excavatum and Prorocentrum micans. Effects of light intensity. In: Okaichi $T$, Anderson DM, Nemoto $T$ (eds) Red tides: biology environmental science and toxicology. Elsevier, New York, p $333-336$

Davidson AT (1996) Natural UVB exposure changes the species composition of Antarctic phytoplankton in mixed culture. Aquat Microb Ecol 10:299-305

Davidson AT, Bramich D, Marchant HJ, McMinn A (1994) 
Effects of UV-B irradiation on growth and survival of Antarctic marine diatoms. Mar Biol 119:507-515

Driscoll CMH, Whillock MJ, Pearson AJ, Gall A, Clark IE, Blackwell RP, McKinlay AF (1990) Solar radiation measurements at three sites in the UK, May 1989-April 1990. NRPB-M256. National Radiological Protection Board, Chilton, Didcot

Fredenck JE, Erlick C (1995) Trends and interannual vandtions in erythemal sunlight, 1978-1993. Photochem Photobiol 62:476-484

Fleischmann EM (1989) The measurement and penetration of ultraviolet radiation in tropical marine water Limnol Oceanogr 34:1623-1629

Garcia-Pichel F, Castenholz RW (1991) Characterisation and biological implications of scytonemin, a cyanobacterial sheath pigment. J Phycol 27:395-409

Garcia-Pichel F, Sherry ND, Castenholz RW (1992) Evidence for an ultraviolet sunscreen role of the extracellular pigment scytonemin in terrestrial cyanobacterium Chlorogloeopsis sp. Photochem Photobiol 56:17-23

Garcia-Pichel F, Wingard CE, Castenholz RW (1993) Evidence regarding the UV sunscreen role of a mycosporinelike compound in the Cyanobacterium Gloeocapsa sp. Applied Environ Microbiol 59:170-176

Hager A (1980) The reversible light-induced conversions of xanthophylls in the chloroplast. In: Czygan FC (ed) Pigments in plants. Fischer, Stuttgart, p 57-59

Helbling EW, Villafane V, Ferrario M, Holm-Hansen O (1992) Impact of natural ultraviolet radiation on rates of photosynthesis and on specific marine phytoplankton species. Mar Ecol Prog Ser 80:89-100

Karentz D, Lutze LH (1990) Evaluation of biologically harmful ultraviolet radiation in Antarctica with a biological dosimeter designed for aquatic environments. Limnol Oceanogr 35:549-561

Karentz D, McEuen FS, Land MC, Dunlap WC (1991) Survey of mycosporine-like amino acid compounds in Antarctic marine organisms: potential protection from ultraviolet exposure. Mar Biol 108:157-166

Llewellyn CA, Mantoura RFC (1996) Pigment biomarkers and particulate carbon in the upper water column compared to

Editorial responsibulity: Otto Kinne (Editor),

Oldendorf/Luhe, Germany the ocean interior of the northeast Atlantic. Deep Sea Res 43:1165-1184

Morel A, Antoine D (1994) Heating rate within the Upper Ocean in relation to its bio-optical state. J Phys Oceanogr $24: 1652-1665$

Negri RM, Carreto Jl, Benavides HR, Akselman R, Lutz VA (1992) An unusual bloom of Gyrodinium of. aureolum in the Argentine sea: community structure and conditioning factors. J Plankton Res 14:261-269

Proteau PJ, Gerwick WH, Garcia-Pichel F, Castenholz RW (1993) The structure of scytonemin, an ultraviolet sunscreen pigment from the sheaths of cyanobacteria. Experientia 49:825-829

Roy CR, Gies HP, Elliott G (1990) Ozone depletion. Nature $347: 235-236$

Schindler DW, Curtis PJ, Parker BR, Stainton MP (1996) Consequences of climate warming and lake acidification for UV-B penetration in North American boreal lakes. Nature 379:705-708

Shick JM, Dunlap WC, Chalker BE, Banaszak AT (1992) Survey of ultraviolet radiation-absorbing mycosporine-like amino acids in organs of coral reef holothuroids. Mar Ecol Prog Ser 90:139-148

Stolarski R, Bojkov R, Bishop L, Zerefos C, Staehelin J, Zawadony $J$ (1992) Measured trends in stratospheric ozone. Science 256:342-349

Vernet $M$, Neori A, Haxo FT (1989) Spectral properties and photosynthetic action in red-tide populations of Prorocentrum micans and Gonyaulax polyedra. Mar Biol 103: $365-371$

Vincent WF, Downes MT, Castenholz RW, Howard-Williams C (1993) Community structure and pigment organisation of cyanobacteria-dominated microbial mats in Antarctica. Eur J Phycol 28:213-221

Weeks A, Conte $\mathrm{MH}$, Harris RP, Bedo A, Bellan I, Burkill PH, Edwards ES, Harbour DS, Kennedy H, Llewellyn CA, Mantoura RFC, Morales CE, Pomroy AJ, Turley CM (1993) The physical and chemical environment and changes in community structure associated with bloom evolution: the Joint Global Flux Study North A.tlantic Bloom Experiment. Deep Sea Res 40:347-368

Submitted: April 16, 1997, Accepted: September 10, 1997 Proofs received from author(s): October 24, 1997 